\title{
Sea ice kinematic features in the Arctic outflow region and their associations with Arctic Northeast Passage accessibility
}

GUI Dawei $^{1,2}$, PANG Xiaoping ${ }^{1}$, LEI Ruibo ${ }^{2,1^{*}}$, ZHAO Xi ${ }^{1}$, WANG Jia ${ }^{3}$

${ }^{1}$ Chinese Antarctic Center of Surveying and Mapping, Wuhan University, Wuhan 430079, China;

${ }^{2}$ SOA Key Laboratory for Polar Science, Polar Research Institute of China, Shanghai 200136, China;

${ }^{3}$ National Oceanic and Atmospheric Administration Great Lakes Environmental Research Laboratory, Ann Arbor, USA.

* Corresponding author

Keywords: Arctic sea ice, Remote sensing product, Arctic Northeast Passage, Atmospheric circulation indices

\begin{abstract}
:
Increasing amounts of evidence have proven Arctic sea ice is undergoing remarkable loss. On the bright side, the Arctic sea routes are becoming increasingly accessible. In this study, the NSIDC product of sea ice motion was applied to reconstruct the northward speed of sea ice to obtain the kinematic features of the sea ice in the Arctic outflow region which specially referred to the Fram Strait and to the north of the Northeast Passage (NEP).

In the Arctic outflow region, the average southward displacement of sea ice in 2007-2014 (1511 km) was more than twice the average prior to $2007(617 \mathrm{~km})$, which indicated continuous enhancement of the Transpolar Drift Stream (TDS) in comparison with previous years. In the regions to the north of the NEP, the long-term trend of northward sea ice speed in the Kara sector was $+0.04 \mathrm{~cm} \mathrm{~s}^{-1}$ year $^{-1}$ in spring. A significant statistical relationship was found between the NEP open period and the northward speed of the sea ice to the north of the NEP. The offshore advection of sea ice could account for the opening of sea routes by $33 \%$ and $15 \%$ in the Kara and Laptev sectors, respectively.

The atmospheric circulation indices across the TDS, i.e., the Central Arctic Index (CAI), presented more significant correlation than for the Arctic atmospheric Dipole Anomaly index with the open period of the NEP, and the CAI could explain the southward displacement of sea ice toward Fram Strait by more than 45\%. The impact from the summer positive CAI reinforces the thinning and mechanical weakening of the sea ice in the NEP region, which promoted the navigability of the NEP.
\end{abstract}

